\title{
ESTUDO DAS MODIFICAÇÕES DAS PROPRIEDADES FÍSICO-QUÍMICAS DE FLUIDOS DE PERFURAÇÃO AQUOSOS
}

\author{
Jefferson Horst de Almeida ${ }^{1}$, Luiz Henrique Poley Victer Dias ${ }^{2}$ \& Wagner da Silva Terra ${ }^{3 *}$
}

\section{RESUMO}

ALMEIDA, J.H.; DIAS, L.H.P.V.; TERRA, W.S. Estudo das Modificações das Propriedades Físico-Químicas de Fluidos de Perfuração Aquosos. Perspectivas Online: Exatas \& Engenharia, v. 10, n. 28, p. 17-39, 2020.

O estudo das propriedades físico-químicas dos fluidos de perfuração é de grande importância para a indústria petrolífera. Nesse contexto, o presente trabalho teve por intuito sintetizar três fluidos de perfuração com diferentes composições químicas (Fluidos 1, 2 e 3), permitindo que algumas das suas propriedades fossem determinadas, tais como, densidade, parâmetros reológicos, filtrado e reboco, salinidade e pH. Após a realização das análises observou-se que o nitrato de bário não apresentou eficiência como adensante, pois sua adição afetou as interações entre as moléculas, gerando uma redução na viscosidade. Apesar do Fluido 2 apresentar algumas características interessantes para a indústria petrolífera a adição do adensante selecionado não foi adequada para $o$ preparo desse fluido.

Palavras-chave: Fluido de Perfuração; Propriedades Físico-Químicas; Fluidos Aquosos

\footnotetext{
${ }^{1}$ Falcão Bauer Centro Tecnológico de Controle e Qualidade, R. Aquinos, 111, Água Branca,CEP:05036-070, São Paulo, SP, Brasil.

${ }^{2}$ Universidade Estácio de Sá, Avenida 28 de Março, 423, Centro, CEP: 28020-740, Campos dos Goytacazes, RJ, Brasil ${ }^{3}$ Instituto Federal Fluminense, Rua Dr. Siqueira, 273, Parque Dom Bosco, CEP: 28030-130, Campos dos Goytacazes, RJ, Brasil

(*) e-mail: wagnerdasilvaterra@yahoo.com.br
} 


\title{
STUDY OF CHANGES IN PHYSICAL AND CHEMICAL PROPERTIES OF AQUEOUS DRILLING FLUIDS
}

\author{
Jefferson Horst de Almeida ${ }^{1}$, Luiz Henrique Poley Victer Dias ${ }^{2}$ \& Wagner da Silva Terra ${ }^{3 *}$
}

\begin{abstract}
ALMEIDA, J.H.; DIAS, L.H.P.V.; TERRA, W.S. Study of changes in physical and chemical properties of aqueous drilling fluids (In Portuguese). Perspectivas Online: Exatas \& Engenharia, v. 10, n. 28, p. 17-39, 2020.

The study of the physical and chemical properties of drilling fluids is of great importance for the oil industry. In this context, the present work aimed to synthesize three drilling fluids with different chemical compositions (Fluids 1, 2 and 3), allowing some of their properties to be determined, such as density, rheological parameters, filtrate parameters, salinity and $\mathrm{pH}$. After carrying out the

analyzes, it was observed that the barium nitrate was not efficient as weighting agent, since its addition affected the interactions between the molecules, generating a reduction in viscosity. The Fluid 2 presented some interesting characteristics for the oil industry, but the addition of the selected weighting agent was not suitable for the preparation of this fluid.
\end{abstract}

Keywords: Drilling Fluid; Physical-Chemical Properties; Aqueous Fluids

\footnotetext{
${ }^{1}$ Falcão Bauer Technological Control and Quality Center, Street Aquinos, 111, Água Branca, Postal code: 05036-070, São Paulo, SP, Brazil;

${ }^{2}$ Universidade Estácio de Sá, 28 de Março Avenue, 423, City center, Postal code: 28020-740, Campos dos Goytacazes, RJ, Brazil;

${ }^{3}$ Federal Fluminense Institute, Rua Dr. Siqueira, 273, Parque Dom Bosco, Postal code: 28030-130, Campos dos Goytacazes, RJ, Brazil;

(*) e-mail: wagnerdasilvaterra@yahoo.com.br
} 


\section{INTRODUÇÃO}

Os investimentos na indústria petrolífera vêm desempenhando relevantes atribuições no desenvolvimento da economia brasileira e mundial (PIQUET e SERRA, 2007; FERREIRA et al., 2020). Por muitas décadas, o petróleo foi um dos principais estimuladores da economia internacional, atingindo seu ápice no início dos anos 70, quando quase $50 \%$ de todo consumo de energia primária do mundo era proveniente desse recurso energético. Nos últimos anos vêm sendo observado um leve declínio dessa porcentagem. Apesar disso, essa fonte energética ainda permanecerá por décadas impulsionando, de forma significativa, a economia tanto brasileira, como mundial (FERREIRA et al., 2020). Esse fato é devido à grande importância desse produto para a ascensão de grandes potências, principalmente como fonte de energia, o que potencializa sua função estratégico-militar e influência drasticamente alguns conflitos socioeconômicos da atualidade (FRERET et al, 2019; BYAKAGABA et al., 2019; GASTALDI e MENDONÇA, 2019). Portanto, o petróleo se apresenta como um recurso estratégico extremamente relevante, uma vez que seus derivados são utilizados por grande parte das formas de transporte. Além disso, outros produtos de origem petrolífera são amplamente requeridos pela sociedade moderna (FERREIRA et al., 2020).

A etapa de Exploração e Produção (E\&P), também denominada por upstream, envolve atividades de alto risco de insucesso, maiores taxas de incidentes na indústria petrolífera e elevados custos inerentes aos projetos de prospecção e perfuração exploratória (BHADARI et al., 2015; VANDENBUSSCHE et al., 2012; PIQUET et al., 2017). No Brasil, os custos inerentes a essa etapa são ainda mais significativos, pois essas ocorrem, muita das vezes, em águas profundas (TRINDADE e BRANCO, 2005). Além disso, o petróleo produzido apresenta uma composição química muito variável, a qual é bastante dependente de sua origem e dos processos geoquímicos que foram submetidos, sendo a determinação dessas características um fator bastante importante para o processo de produção desse fluido (AZEVEDO et al. 2009; TERRA et al., 2019). Portanto, torna-se necessário o uso de tecnologias modernas, equipamentos de primeiro mundo, serviços bastante especializados e investimentos em novos processos de exploração e produção, para que assim esses custos sejam minimizados com o máximo de segurança possível (PIQUET et al., 2017).

Basicamente existem dois métodos para perfuração de um poço de petróleo: o rotativo e o percussivo, porém, em grande parte das perfurações de poços no mundo utiliza-se o método rotativo (AQUINO e COSTA, 2011). Neste método, a broca fragmenta a rocha devido à velocidade de rotação aplicada e ao peso da coluna de perfuração, que possui tubos grandes e de elevada massa, denominados de comandos ou heavy weight drill pipes. Assim, a coluna de perfuração transmite torque do sistema de acionamento para a broca e a perfuração é promovida (JANSEN e VAN DEN STEEN, 1995; THOMAS, 2001). Durante o processo de perfuração, os cascalhos gerados são levados até a superfície por uma mistura denominada fluido ou lama de perfuração, que é bombeada por dentro da coluna e retorna pelo espaço anular existente entre o poço perfurado e a coluna de perfuração (FISCHER e COOK, 1951; QUEIROZ-NETO et al., 2007; NASIRI et al., 2009).

Os processos de perfuração, bem como a produção petrolífera atual, só podem ser realizados devido a existência dos fluidos de perfuração, os quais são definidos como qualquer fluido circulante que auxilie a perfuração de poços de petróleo, poços tubulares e

Persp. Online: exatas \& eng., Campos dos Goytacazes, 28 (10) 17 - 39 - 2020

https://ojs3.perspectivasonline.com.br/ 
operações de sondagem (THOMAS, 2001; BORGES et al., 2009; BARBOSA et al., 2007). Esses fluidos podem também ser definidos como misturas complexas de sólidos, líquidos e, algumas vezes, até gases, que, quimicamente assumem aspectos de suspensão, dispersão coloidal ou emulsão, dependendo dos estados de agregação dos componentes da mistura (FARIAS et al., 2009).

Os fluidos de perfuração são indispensáveis para a produção petrolífera atual, pois são responsáveis por uma série de funções essenciais, sendo essas dependentes das propriedades físico-químicas dos aditivos incorporados nesses fluidos. Dentre essas propriedades destacamse densidade, viscosidade, tipo e velocidade de gelificação, quantidade de filtrado e reboco, inibição das argilas hidratáveis, pH, sólidos totais, entre outras (BARBOSA et al., 2007; CAENN e CHILLINGAR, 1996). O controle correto dessas propriedades pode potencializar e permitir o manejo das funções dos fluidos de perfuração. Entre as principais funções desses, destacam-se: permitir a limpeza e desobstrução do poço por meio da retirada dos cascalhos gerados durante o processo de perfuração; aumentar a taxa de penetração da broca na rocha; manter a estabilidade do poço; resfriar e lubrificar a broca (CAENN e CHILLINGAR 1996; MAHMOUD e DARDIR, 2010; NASIRI et al., 2009).

A formulação ideal permite que um fluido de perfuração apresente um comportamento quimicamente estável, seja inerte as rochas a serem perfuradas, seja capaz de aceitar tratamentos químicos e físicos, apresente baixos potenciais de corrosão, abrasão e agressão ao meio ambiente e, além disso, permita o seu bombeamento por todo sistema de circulação (THOMAS, 2001; KEMBAIYAN e KESHAVAN, 1995; NASIRI et al., 2009). Essas características também podem ser controladas pelas alterações nas composições químicas desses fluidos, o que pode minimizar ou, até mesmo, eliminar diversos problemas presentes na indústria petrolífera, tais como: a perda da circulação do fluido, a ineficiência na limpeza do poço e a possibilidade de danificar o meio ambiente (SORGARD et al.,2001).

Tradicionalmente, a classificação dos fluidos de perfuração está relacionada ao constituinte principal desses fluidos, ou seja, ao meio dispersante. Embora ocorra divergências, os fluidos podem ser classificados de acordo com três categorias básicas, sendo estas: fluidos aquosos, fluidos oleosos ou sintéticos e fluidos aerados. O tipo de fluido a ser utilizado depende, principalmente, do tipo de rocha e da profundidade ou espessura das formações a serem perfuradas (BORGES et al., 2009; FARIAS et al., 2009).

Dentre os tipos de fluidos, os aquosos se destacam tanto no Brasil como no mundo, principalmente por serem considerados ambientalmente seguros, mais baratos e apresentarem baixas toxicidade e bioacumulação (AMORIN et al, 2005; BORGES et al., 2009). Além disso, esse tipo de fluido permite a utilização de polímeros orgânicos, para permitir que a viscosidade ideal seja atingida, de tal modo que as quantidades de sólidos e a invasão de filtrado na formação seja minimizada (MAHTO e SHARMA, 2004). Contrapondo a esse tipo de fluido, os que são a base não aquosa ou sintética apresentam características que podem minimizar inúmeros problemas durante a perfuração de um poço, como por exemplo: lubricidade, fricção mecânica, inibição química e estabilidade do sistema (CURBELO et al., 2017). Esse tipo de fluido foi desenvolvido com intuinto de ser utilizado em situações em que os fluidos a base de água apresentavam limitações técnicas e operacionais (ECCARD et al., 2018).

Persp. Online: exatas \& eng., Campos dos Goytacazes, 28 (10) 17 - 39 - 2020

https://ojs3.perspectivasonline.com.br/ 
Diante desse contexto o presente trabalho tem como objetivo sintetizar três fluidos de perfuração de base aquosa utilizando diferentes composições químicas, a fim de verificar as modificações físico-químicas apresentadas pelos diferentes aditivos utilizados nos fluidos.

\section{METODOLOGIA}

\subsection{Síntese e composição dos fluidos de perfuração}

Com o intuito de averiguar a influência de diferentes composições nas propriedades físico-químicas dos fluidos de perfuração aquosos foram sintetizadas três misturas, denominadas de Fluidos 1, 2 e 3, com diferentes aditivos conforme quantidades préestabelecidas na Tabela 1. É importante evidenciar que as substâncias químicas utilizadas nessa pesquisa apresentaram grau P.A. (Para Análise) de pureza, sendo adquiridas de fontes comerciais e utilizadas sem prévio tratamento.

Tabela 1: Composição dos fluidos de perfuração.

\begin{tabular}{lccc}
\hline \multicolumn{1}{c}{ Aditivos } & Fluido 1 & Fluido 2 & Fluido 3 \\
\hline Nitrato de Bário (g) & 10,0499 & 10,0099 & 20,0791 \\
Hidróxido de Sódio (g) & 0,5021 & 0,5082 & 0,5010 \\
Cloreto de Potássio (g) & 9,0072 & 9,0374 & 9,0041 \\
Goma Xantana (GX) (g) & 5,0123 & - & - \\
Carboximetilcelulose (CMC) (g) & - & 5,0091 & 5,0782 \\
\hline
\end{tabular}

As substâncias químicas foram selecionadas de acordo com suas disponibilidades no laboratório, características químicas e possibilidade de alterações nas diferentes propriedades físico-químicas dos fluidos sintetizados, tais como: $\mathrm{pH}$, densidade, viscosidade, força gel, espessura do reboco e quantidade de filtrado. As referidas sínteses e análises foram realizadas no Laboratório de Petróleo, nas dependências do Instituto Federal Fluminense.

As massas dos aditivos presentes na Tabela 1 foram obtidas por meio de uma balança analítica da marca Bioscale, modelo FA-2204-BI. Em seguida, os agentes viscosificantes (Goma Xantana ou Carboximetilcelulose) foram transferidos lentamente sob agitação para o copo coletor do misturador Hamilton Beach (modelo 936) que continha previamente $350,00 \mathrm{~mL}$ de água deionizada, o que auxiliou o processo de hidratação dos polímeros utilizados. Após completa homogeneização do fluido, os demais aditivos foram adicionados com auxílio de uma espátula metálica e as misturas obtidas deixadas sob agitação por 30 minutos.

Após obtenção, os três fluidos permaneceram em repouso por aproximadamente $20 \mathrm{~h}$ a temperatura ambiente. Ao término do tempo especificado realizou-se diferentes análises com intuito de verificar as influências das quantidades de andensante e dos tipos de agentes viscosificantes nas propriedades físico-químicas das misturas obtidas, possibilitando possíveis aplicações na indústria de perfuração de poços petrolíferos. Além disso, é importante destacar que todas as análises foram realizadas em triplicatas, visando resultados com maior precisão,

Persp. Online: exatas \& eng., Campos dos Goytacazes, 28 (10) 17 - 39 - 2020

https://ojs3.perspectivasonline.com.br/ 
exatidão e confiabilidade.

\subsection{Densidade}

As densidades dos fluidos sintetizados foram determinadas utilizando Balança de Lama da Fann Instrument Company, modelo 140, previamente calibrada com água deionizada. Cada uma das misturas produzidas foi adicionada separadamente até o limite máximo do copo da balança, que, em seguida, foi tampado de forma adequada. Logo após, uma peça móvel foi ajustada até que o instrumento atingisse seu equilíbrio dinâmico, o que foi determinado por meio de um nível de bolha na parte superior do equipamento. Após devidamente equilibrado, a leitura do instrumento foi registrada tanto em $\mathrm{g} . \mathrm{cm}^{-3} \mathrm{como} \mathrm{em}$ lb.gal ${ }^{-1}$.

\subsection{Análises reológicas}

As propriedades reológicas dos fluidos sintetizados foram obtidas em um reômetro da marca Fann Instrument Company, modelo 35 A (F1-B1), com calibração previamente verificada por meio de padrões de viscosidade da Brookfield $(100$ e $500 \mathrm{cP})$.

Inicialmente cada uma das amostras foram devidamente homogeneizadas e colocadas separadamente no reservatório metálico do viscosímetro até a marca interna presente no recipiente de análise. Em seguida o reservatório foi movido de tal modo que o fluido atingisse a marca localizada na parte superior do rotor, imergindo-o na profundidade apropriada para análise. Após ajuste do zero, cada um dos fluidos foi agitado a velocidade de $600 \mathrm{rpm}$ durante 1 minuto, e, ao final desse tempo, pode-se efetuar a leitura da deflexão $(\theta)$ nessa velocidade de rotação $\left(\mathrm{L}_{600}\right)$. O procedimento foi seguido da mesma maneira para as velocidades de 300 , 200, 100, 6 e 3 rpm, sempre deixado sob 1 minuto de agitação em cada velocidade e logo em seguida realizada a leitura do ângulo de deflexão correspondente. Após obtenção dos ângulos em cada rotação, as Equações 1 e 2 foram utilizadas para obtenção dos valores de taxas $(\gamma)$ e tensões $(\tau)$ de cisalhamento, que permitiram a construção das curvas reológicas para cada um dos três fluidos sintetizados (MACHADO, 2002).

$$
\tau=\left(\frac{k}{2 \pi r_{1}^{2} H}\right) \theta=0,51 \theta \quad \text { (1) } \quad \gamma=\psi\left(\frac{2 r_{2}^{2}}{r_{2}^{2}-r_{1}^{2}}\right) \omega=1,703 N \quad \text { (2) } \therefore \quad \omega=\frac{2 \pi}{60} N
$$

Onde, $\mathrm{k}=$ Constante da mola de torção $\left(3,87 \cdot 10^{-5} \mathrm{~N} \cdot \mathrm{m} \cdot \mathrm{grau}^{-1}\right) ; \mathrm{r}_{1}=$ Raio do cilindro interno $\left(\mathrm{r}_{1}=1,7254.10^{-2} \mathrm{~m}\right) ; \mathrm{H}=$ Altura de imersão estipulado pelo instrumento $\left(\mathrm{H}=4,05.10^{-2}\right.$ $\mathrm{m}) ; \mathrm{r}_{2}=$ Raio do cilindro externo $\left(\mathrm{r}_{2}=1,845.10^{-2} \mathrm{~m}\right) ; \psi=$ Fator de correção das taxas de cisalhamento para fluidos não newtonianos $(\psi=1$, quando $\mathrm{n}=1$, onde $\mathrm{n}$ equivale ao índice de fluxo); $\omega=$ velocidade angular do cilindro de rotação $\left(\operatorname{rad} . \mathrm{s}^{-1}\right) ; \tau=$ Tensão de cisalhamento $\left(\mathrm{N} . \mathrm{m}^{-2}\right)$ e $\gamma=$ Taxa de cisalhamento $\left(\mathrm{s}^{-1}\right)$.

Ao final desse procedimento foi possível determinar as viscosidades plástica e aparente, a classificação do fluido, o limite de escoamento e o índice de consistência para cada um dos fluidos analisados empregando as Equações 3, 4, 5, 6 e 7 (MACHADO 2002).

Persp. Online: exatas \& eng., Campos dos Goytacazes, 28 (10) 17 - 39 - 2020

https://ojs3.perspectivasonline.com.br/ 


$$
\begin{gathered}
\mu_{a}(c P)=\frac{L_{600}}{2} \text { (3) } \mu_{p}=L_{600}-L_{300} \quad \text { (4) } \tau_{L}\left(l b f \cdot 10^{-2} f t^{-2}\right)=L_{300}-\mu_{p} \\
n=3,32 \log \frac{L_{600}}{L_{300}}(6) \quad k\left(l b f . s^{n} \cdot 10^{-2} \cdot f t^{-2}\right)=1,066 \frac{L_{600}}{1022^{n}}
\end{gathered}
$$

Onde, $\mu_{\mathrm{a}}=$ viscosidade aparente $(\mathrm{cP}) ; \mu_{\mathrm{p}}=$ viscosidade plástica $(\mathrm{cP}) ; \tau_{\mathrm{L}}=$ limite de escoamento (lbf. $\left.10^{-2} \mathrm{ft}^{-2}\right) ; \mathrm{n}=$ índice de fluxo (adimensional); $\mathrm{k}=$ índice de consistência (lbf.s $\left.\mathrm{s}^{\mathrm{n}} \cdot 10^{-2} . \mathrm{ft}^{-2}\right) ; \mathrm{L}_{600}=$ leitura de deflexão a $600 \mathrm{rpm}\left(\mathrm{lb} \cdot 10^{-2} \mathrm{ft}^{-2}\right)$ e $\mathrm{L}_{300}=$ leitura de deflexão a $300 \mathrm{rpm}\left(\mathrm{lb} \cdot 10^{-2} \mathrm{ft}^{-2}\right)$.

Para determinação das forças géis foi utilizado o mesmo reômetro do experimento anterior. Inicialmente o equipamento foi acionado na velocidade de $600 \mathrm{rpm}$ durante 1 minuto, o que resultou na agitação dos fluidos sintetizados. Após o tempo determinado, o equipamento foi desligado e imediatamente foram cronometrados 10 segundos de repouso. Ao completar esse tempo, a alavanca que determina a rotação foi colocada na posição de 3 rpm, tornando possível realizar a leitura da maior deflexão obtida, sendo essa considerada a força gel inicial $\left(\mathrm{G}_{0}\right)$. Em seguida, repetiu-se o experimento sendo substituído o tempo de repouso para 10 minutos, no caso do $\mathrm{G}_{10}$, e 30 minutos, no caso do $\mathrm{G}_{30}$. Por fim, já com as leituras obtidas foi possível classificar devidamente os fluidos quanto à força gel.

\subsection{Análises de pH}

Uma fração do fluido foi transferida para 2 tubos de ensaio, os quais foram centrifugados por 10 minutos em uma rotação de $1500 \mathrm{rpm}$, utilizando uma Centrífuga Fanem. Posteriormente, o $\mathrm{pH}$ do sobrenadante de cada um dos três fluidos foi analisado utilizando um pHmetro da Tecnopon Instruments, modelo mPA-210.

\subsection{Determinação dos parâmetros de filtração e reboco}

O teor de filtrado e a espessura do reboco foram determinados utilizando um Filtro Prensa tipo API da Fann Instruments, modelo 300. Primeiramente foi colocado na parte inferior do reservatório para coleta de fluidos uma folha de papel de filtro Whatman $n^{\circ} 50$ de $9 \mathrm{~cm}$, essa foi utilizada como meio filtrante para permitir a passagem da parte dispersante presente nos fluidos. Após o equipamento ser corretamente condicionado o fluido foi adicionado ao seu reservatório, tendo o cuidado de preenchê-lo até a marca encontrada em seu interior, permitindo que $7 \mathrm{in}^{2}\left(0,0045 \mathrm{~m}^{2}\right)$ entrem em contato com cada um dos fluidos. Após a adição de uma proveta graduada de $10 \mathrm{~mL}$ na parte inferior do Filtro Prensa o reservatório do equipamento foi pressurisado a 80 Psi por 30 minutos utilizando um cilindro de óxido nitroso $\left(\mathrm{N}_{2} \mathrm{O}\right)$. Após o tempo estipulado o filtrado foi quantificado, em $\mathrm{mL}$, por meio da leitura na proveta graduada e a espessura do reboco formado foi determinada, em $\mathrm{mm}$, utilizando uma régua graduada. O filtrado obtido para cada um dos fluidos foi cuidadosamente armazenado para que as suas salinidades fossem determinadas.

\subsection{Determinação da salinidade}

A salinidade do meio dispersivo de cada uma das três misturas foi obtida utilizando o método titulométrico de Mohr. Nesse procedimento uma mistura contendo $400 \mu \mathrm{L}$ do filtrado,

Persp. Online: exatas \& eng., Campos dos Goytacazes, 28 (10) 17 - 39 - 2020

https://ojs3.perspectivasonline.com.br/ 
$40 \mathrm{~mL}$ de água deionizada e $1 \mathrm{~mL}$ do indicador cromato de potássio $\left(\mathrm{K}_{2} \mathrm{CrO}_{4}\right)$ a $5 \%\left(\mathrm{~m}^{-1} \mathrm{v}^{-1}\right)$ foi titulada com uma solução previamente padronizada de nitrato de prata $\left(\mathrm{AgNO}_{3}\right)$ 0,00980 mol. $\mathrm{L}^{-1}$. Ao final das titulações, os volumes gastos do titulante foram subtraídos da média dos volumes gastos nas titulações sem a presença do filtrado (teste em branco). Com o volume final, foram realizados cálculos estequiométricos para obtenção do teor de salinidade.

\subsection{Retorta}

No recipiente dentro da câmara de aquecimento do equipamento de retorta (Fann Instruments) foram adicionados separadamente $10 \mathrm{~mL}$ de cada um dos fluidos sintetizados. Após o processo de destilação ser iniciado obteve-se o destilado, o qual foi coletado em uma proveta graduada de $10 \mathrm{~mL}$ na extremidade final do condensador presente no equipamento. Por meio das leituras dos volumes obtidos ( $\left.\mathrm{V}_{\text {óleo }} \mathrm{e} \mathrm{V}_{\text {água }}\right)$ foi possível determinar os parâmetros de retorta aplicando as equações abaixo:

$$
\begin{aligned}
& \%_{\text {óleo }}=V_{\text {óleo }} .10 \quad \text { (8) } \quad m_{\text {óleo }}(g)=V_{\text {óleo }} \cdot 0,8 \quad \text { (9) } \quad \%_{\text {água }}=V_{\text {água }} \cdot 10 \\
& m_{\text {água }}(g)=V_{\text {água }} \cdot 1,0 \quad(\mathbf{1 1}) \quad \%_{\text {sólido }}=100-\left(V_{\text {óleo }}+V_{\text {água }}\right) \cdot 10 \\
& m_{\text {fluido }}(g)=\rho_{\text {fluido }}\left(\text { lb.gal }{ }^{-1}\right) \cdot 1,2 \quad \text { (13) } m_{\text {st }}(g)=m_{\text {fluido }}-\left(m_{\text {óleo }}+m_{\text {água }}\right) \\
& V_{s t}(m L)=10-\left(V_{\text {óleo }}+V_{\text {água }}\right)(\mathbf{1 5}) \quad \rho_{s t}\left(g \cdot m L^{-1}\right)=\frac{m_{s t}}{V_{s t}}(\mathbf{1 6}) \quad \%_{s t}=\frac{m_{\text {st }} \cdot 100}{m_{\text {fluido }}} \\
& \% \text { água corrigida }(\text { Real })=\% \text { água } \cdot\left\{1+1,3 \cdot 10^{-8} \cdot\left[C_{N a C l}(p p m)\right]^{1,29}\right\} \\
& \%_{\text {sólidos corrigidos }(\text { Real })}=100-\% \text { óleo }-\% \text { água corrigida }(\text { Real })
\end{aligned}
$$

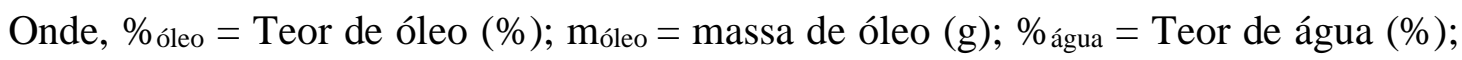
$\mathrm{m}_{\text {água }}=$ massa de água $(\mathrm{g}) ; \%$ sólido $=$ Teor de sólidos $(\%) ; \mathrm{m}_{\text {fluido }}=$ massa de fluido $(\mathrm{g}) ; \rho_{\text {fluido }}=$ densidade do fluido $\left(\mathrm{lb}_{\mathrm{gal}}{ }^{-1}\right) ; \mathrm{m}_{\mathrm{st}}=$ massa de sólidos totais $(\mathrm{g}) ; \mathrm{V}_{\mathrm{st}}=$ volume de sólidos totais $(\mathrm{mL}) ; \rho_{\mathrm{st}}=$ densidade dos sólidos totais $\left(\mathrm{g} \cdot \mathrm{mL}^{-1}\right) ; \%_{\mathrm{st}}=$ Teor de sólidos totais $(\%) ; \%$ água corrigida (Real) $=$ Teor de água corrigida pela salinidade $(\%) ; \mathrm{C}_{\mathrm{NaCl}}=$ Concentração de $\mathrm{NaCl}(\mathrm{ppm})$ e $\%_{\text {sólidos corrigida }(\text { Real })}=$ Teor de sólidos corrigidos pela salinidade $(\%)$.

\section{RESULTADOS E DISCUSSÃO}

\subsection{Síntese e composição dos fluidos de perfuração}

A escolha das substâncias que compuseram os fluidos de perfuração foi feita de forma criteriosa, com a finalidade de apresentar as modificações nas propriedades das misturas produzidas. As diferenças entre as composições de cada um dos fluidos são apresentadas na Tabela 1 e basicamente se diferem quanto a quantidade de nitrato de bário $\left[\mathrm{Ba}\left(\mathrm{NO}_{3}\right)_{2}\right]$ adicionada e o tipo e a quantidade do agente viscosificante utilizado. Apesar da baritina ser

Persp. Online: exatas \& eng., Campos dos Goytacazes, 28 (10) 17 - 39 - 2020 
um dos principais adensantes de fluidos de perfuração utilizados na indústria, nesse trabalho os fluidos foram preparados com nitrato de bário a fim de avaliar a possibilidade de utilização desse como agente adensante. Além disso, no Fluido 1 foi utilizado como agente viscosificante a goma xantana (GX), a qual foi utilizada a fim de comparação com a carboximetilcelulose (CMC), utilizada nos Fluidos 2 e 3 em quantidades diferentes. $\mathrm{O}$ objetivo da diferenciação desses agentes é a possibilidade de observar as alterações nas propriedades reológicas dos fluidos sintetizados.

O nitrato de bário foi utilizado devido a sua alta solubilidade em água (94 g.L. $\left.\mathrm{L}^{-1}\right)$, sendo superior à apresentada pelo sulfato de bário $\left(<0,01 \mathrm{~g} . \mathrm{L}^{-1}\right)$. Esse parâmetro pode possibilitar uma melhor dispersão química, fazendo com que seja alcançado valores superiores de limite máximo de adensamento. A baixa solubilidade do sulfato de bário pode possibilitar a decantação desse composto, possibilitando uma diminuição da estabilidade da emulsão formada. Sendo assim, a utilização do nitrato de bário foi avaliada nesse trabalho, a fim de verificar sua possibilidade como adensante, bem como a compatibilidade com os agentes viscosificantes utilizados. Cabe ressaltar que o nitrato de bário apresenta um valor comercial superior ao sulfato desse cátion e, além disso, estudos indicam que o íon nitrato apresenta baixa toxicidade, porém ele pode ser convertido em outras formas nitrogenadas mais tóxicas como nitrito e amônia (MATTA e GJYLI, 2018). Ademais, a menor densidade do $\mathrm{Ba}\left(\mathrm{NO}_{3}\right)_{2}$ sugere que um número maior de íons $\mathrm{Ba}^{2+}$ sejam incrementados ao fluido de perfuração a fim de se obter um mesmo valor de densidade, o que possibilita um aumento da toxicidade dos fluidos.

Após o preparo dos três fluidos, verificou-se a formação de espuma, o que possivelmente ocorreu devido ao não envelhecimento dos fluidos de perfuração a temperaturas adequadas em forno Roller Over (NASCIMENTO et al. 2013). Além disso, observou-se uma menor consistência para o Fluido 1, que possivelmente foi afetada pela quantidade e tipo de adensante utilizado, o que possivelmente impediu uma adequada hidratação da GX, processo esse que é indispensável para o preparo de fluidos de perfuração a base de água (MELO et al., 2013).

Cabe ressaltar que a GX é largamente utilizada na indústria petrolífera em quantidades inferiores as empregadas nesse trabalho (MELO et al., 2013). Esse fato é devido à diminuição da viscosidade provocada pelo sal utilizado como adensante, o que provocou a necessidade de uma quantidade superior desse polímero. Esse aumento trouxe outro inconveniente, a formação de pequenos flocos, os quais foram formados devido à alta quantidade de GX necessária para que se atingisse a viscosidade desejada. A espuma e os flocos formados no Fluido 1 indicaram que o nitrato de bário foi incompatível com a GX, de tal forma, que esses compostos não devem ser utilizados em conjunto durante o processo de perfuração. Além disso, os Fluidos 2 e 3 tiveram aspectos muito similares, sendo possível dizer que a quantidade de nitrato de bário adicionada causou uma menor interferência quando comparados ao Fluido 1. No entanto, o adensante utilizado também possibilitou alterações significativas nas consistências desses dois fluidos, sendo essas discutidas nas próximas etapas desse trabalho.

\subsection{Densidade}

A densidade dos fluidos é uma propriedade de extrema importância para o processo de

Persp. Online: exatas \& eng., Campos dos Goytacazes, 28 (10) 17 - 39 - 2020

https://ojs3.perspectivasonline.com.br/ 
perfuração, visto que a pressão hidrostática é basicamente controlada por meio dessa variável para um determinado ponto. Esse fato implica que um fluido de perfuração ideal deve ter sua densidade que possibilite a obtenção de uma pressão hidrostática dentro de uma faixa de trabalho, te tal modo que mantenha a estabilidade do poço perfurado, sem que ocorra fraturas indesejáveis na rocha perfurada. Portanto, a obtenção dessa propriedade para um fluido de perfuração é de extrema importância, sendo então uma das primeiras análises a serem realizadas na confecção de misturas com essa finalidade. Os resultados obtidos para os três fluidos são apresentados na Tabela 2.

Tabela 2: Análise em triplicata de densidade nos fluidos de perfuração.

\begin{tabular}{ccccccc}
\hline & \multicolumn{2}{c}{ Fluido 1 } & \multicolumn{2}{c}{ Fluido 2 } & \multicolumn{2}{c}{ Fluido 3 } \\
\cline { 2 - 7 } $\mathbf{1}$ & $\mathbf{k g . m ^ { - 3 }}$ & $\mathbf{l b . g a l}^{\mathbf{- 1}}$ & $\mathbf{k g . m ^ { - 3 }}$ & $\mathbf{l b . g a l}^{\mathbf{- 1}}$ & kg.m $^{\mathbf{- 3}}$ & $\mathbf{l b . g a l}^{\mathbf{1}}$ \\
$\mathbf{2}$ & 966 & 8,056 & 1045 & 8,715 & 1160 & 9,674 \\
$\mathbf{3}$ & 968 & 8,073 & 1041 & 8,682 & 1159 & 9,666 \\
Média & 965 & 8,048 & 1044 & 8,707 & 1161 & 9,683 \\
Desvio Padrão & 966 & 8,059 & 1043 & 8,701 & 1160 & 9,674 \\
& 1,58 & 0,01270 & 2,082 & 0,01740 & 1,000 & 0,008300 \\
\hline
\end{tabular}

Comparando as densidades obtidas para os Fluidos 1 e 2 foi possível observar que houve um aumento de densidade do Fluido 1 para o Fluido 2, mesmo que a quantidade de adensante tenha sido basicamente a mesma. Essa variação se deu pelo o tipo de viscosificante, visto que a espuma gerada nesse fluido resultou na diminuição da densidade. Essa situação indica a necessidade de se conhecer as substâncias empregadas na síntese de um fluido de perfuração, já que, mesmo possuindo funções principais, algumas características podem alterar outras propriedades da mistura resultante. Além disso, foi observada a necessidade de um envelhecimento adequado do fluido em temperaturas previamente determinadas e/ou a submissão do fluido a um banho térmico com ultrassom. Nesses casos específicos seria observada a diminuição da quantidade de espuma produzida, o que consequentemente aumentaria a densidade da mistura formada. Ademais a utilização do nitrato de bário como adensante propiciou a necessidade de uma quantidade maior de GX no Fluido 1, o que possivelmente potencializou o aumento da quantidade de espuma formada. Nesse caso específico, o agente viscosificante e o adensante utilizados nesse fluido não foram compatíveis entre si, o que causou alterações significativas na densidade da mistura formada.

Com relação a comparação entre os Fluidos 2 e 3 verificou-se que as suas densidades foram diferentes, no entanto essa variação foi relativamente baixa, partindo do fato de que o Fluido 3 possui o dobro da quantidade utilizada de nitrato de bário. Esse resultado sugere que com o aumento na massa de adensante o fluido fica cada vez mais saturado até que a variação seja mínima e se alcance a perda da estabilidade do fluido, gerando assim duas fases. Cada adensante possui sua faixa de adensamento, sendo escolhido de acordo com às características do poço a ser perfurado. Ou seja, mesmo apresentado uma solubilidade superior ao sulfato de bário o nitrato desse cátion não apresentou um grande potencial de adensamento, possivelmente devido a sua menor densidade, quando comparada ao sulfato.

Persp. Online: exatas \& eng., Campos dos Goytacazes, 28 (10) 17 - 39 - 2020

https://ojs3.perspectivasonline.com.br/ 


\subsection{Análises Reológicas}

A partir dos valores de rotação e ângulos de reflexão obtidos para cada um dos três fluidos preparados foi possível construir as Tabelas 3, 4 e 5, sendo cada uma delas direcionada para cada um dos fluidos. Nas tabelas são observados os valores das taxas $(\gamma)$ e tensões $(\tau)$ de cisalhamento obtidas no decorrer dessa análise. Utilizando as médias obtidas pelas triplicatas de cada fluido foi possível determinar parâmetros reológicos como: viscosidades aparente, plástica e absoluta, limite de escoamento, índice de fluxo e índice de consistência, todos demonstrados na Tabela 6.

Tabela 3: Análises reológicas em triplicatas para o Fluido 1.

\begin{tabular}{|c|c|c|c|c|c|c|c|}
\hline \multicolumn{8}{|c|}{\begin{tabular}{|l|} 
Fluido 1 \\
\end{tabular}} \\
\hline & rpm & 600 & 300 & 200 & 100 & 6 & 3 \\
\hline \multirow{3}{*}{1} & $\gamma$ & 1021,8 & 510,90 & 340,60 & 170,30 & 10,218 & 5,1090 \\
\hline & $\theta$ & 21,0 & 14,0 & 11,0 & 8,0 & 3,0 & 3,0 \\
\hline & $\tau$ & 10,71 & 7,14 & 5,61 & 4,08 & 1,53 & 1,53 \\
\hline \multirow{2}{*}{2} & $\theta$ & 20,0 & 13,0 & 10,0 & 7,5 & 3,0 & 2,5 \\
\hline & $\tau$ & 10,20 & 6,63 & 5,10 & 3,82 & 1,53 & 1,27 \\
\hline \multirow{4}{*}{3} & $\boldsymbol{\theta}$ & 20,0 & 13,0 & 11,0 & 8,0 & 3,0 & 3,0 \\
\hline & $\tau$ & 10,20 & 6,63 & 5,61 & 4,08 & 1,53 & 1,53 \\
\hline & ia $\theta$ & 20,3 & 13,3 & 10,7 & 7,8 & 3,0 & 2,8 \\
\hline & lia $\tau$ & 10,37 & 6,80 & 5,44 & 3,99 & 1,53 & 1,44 \\
\hline \multirow{2}{*}{\multicolumn{2}{|c|}{$\begin{aligned} \text { Desvio padrão } & \theta \\
\text { Desvio padrão } & \tau\end{aligned}$}} & 0,577 & 0,577 & 0,577 & 0,3 & 0,0 & 0,3 \\
\hline & & 0,2944 & 0,294 & 0,294 & 0,147 & 0,00 & 0,147 \\
\hline
\end{tabular}

Tabela 4: Análises reológicas em triplicatas para o Fluido 2.

\begin{tabular}{|c|c|c|c|c|c|c|c|}
\hline \multicolumn{8}{|c|}{ Fluido 2} \\
\hline & rpm & 600 & 300 & 200 & 100 & 6 & 3 \\
\hline \multirow{3}{*}{1} & $\gamma$ & 1021,8 & 510,90 & 340,60 & 170,30 & 10,218 & 5,1090 \\
\hline & $\theta$ & 210,0 & 162,0 & 143,0 & 109,0 & 30,0 & 20,0 \\
\hline & $\tau$ & 107,1 & 82,62 & 72,93 & 55,59 & 15,3 & 10,2 \\
\hline \multirow{2}{*}{2} & $\theta$ & 208,0 & 161,0 & 138,0 & 106,0 & 29,0 & 19,0 \\
\hline & $\tau$ & 106,1 & 82,11 & 70,38 & 54,06 & 14,8 & 9,69 \\
\hline \multirow{4}{*}{3} & $\boldsymbol{\theta}$ & 208,0 & 162,0 & 138,0 & 105,0 & 28,0 & 19,0 \\
\hline & $\tau$ & 106,1 & 82,62 & 70,38 & 53,55 & 14,3 & 9,69 \\
\hline & ia $\theta$ & 208,7 & 161,7 & 139,7 & 106,7 & 29,0 & 19,3 \\
\hline & ia $\tau$ & 106,4 & 82,45 & 71,23 & 54,40 & 14,8 & 9,86 \\
\hline \multirow{2}{*}{\multicolumn{2}{|c|}{$\begin{array}{l}\text { Desvio padrão } \theta \\
\text { Desvio padrão } \tau\end{array}$}} & 1,155 & 0,5774 & 2,887 & 2,082 & 1,00 & 0,580 \\
\hline & & 0,5889 & 0,2944 & 1,472 & 1,062 & 0,510 & 0,294 \\
\hline
\end{tabular}

Persp. Online: exatas \& eng., Campos dos Goytacazes, 28 (10) 17 - 39 - 2020 
Tabela 5: Análises reológicas em triplicatas para o Fluido 3.

\begin{tabular}{|c|c|c|c|c|c|c|c|}
\hline \multicolumn{8}{|c|}{ Fluido 3} \\
\hline & rpm & 600 & 300 & 200 & 100 & 6 & 3 \\
\hline \multirow{3}{*}{1} & $\gamma$ & 1021,8 & 510,90 & 340,60 & 170,30 & 10,218 & 5,1090 \\
\hline & $\theta$ & 128,0 & 91,0 & 73,0 & 49,0 & 7,0 & 4,0 \\
\hline & $\tau$ & 65,28 & 46,4 & 37,23 & 24,99 & 3,57 & 2,04 \\
\hline \multirow{2}{*}{2} & $\theta$ & 129,0 & 92,0 & 74,0 & 49,5 & 7,5 & 5,0 \\
\hline & $\tau$ & 65,79 & 46,9 & 37,74 & 25,24 & 3,82 & 2,55 \\
\hline \multirow{4}{*}{3} & $\boldsymbol{\theta}$ & 129,0 & 91,5 & 74,0 & 49,5 & 7,5 & 5,0 \\
\hline & $\tau$ & 65,79 & 46,7 & 37,74 & 25,24 & 3,82 & 2,55 \\
\hline & ia $\theta$ & 128,7 & 91,5 & 73,7 & 49,3 & 7,3 & 4,7 \\
\hline & lia $\tau$ & 65,62 & 46,7 & 37,57 & 25,16 & 3,74 & 2,38 \\
\hline \multirow{2}{*}{\multicolumn{2}{|c|}{$\begin{array}{l}\text { Desvio padrão } \theta \\
\text { Desvio padrão }\end{array}$}} & 0,5774 & 0,500 & 0,577 & 0,288 & 0,29 & 0,58 \\
\hline & & 0,2944 & 0,255 & 0,2944 & 0,1472 & 0,147 & 0,294 \\
\hline
\end{tabular}

Tabela 6: Análise de viscosidade da média das triplicatas dos fluidos de perfuração.

\begin{tabular}{|c|c|c|c|}
\hline Propriedades & Fluido 1 & Fluido 2 & Fluido 3 \\
\hline$\left(\mu_{a}\right)$ Visc. Aparente (cP) & 10,17 & 104,3 & 64,33 \\
\hline$\left(\mu_{\mathrm{p}}\right)$ Visc. Plástica $(\mathrm{cP})$ & 7,000 & 47,00 & 37,17 \\
\hline$\left(\tau_{L}\right)$ Limite de Escoamento $\left({ }^{\prime b f .10} 0^{-2} \mathrm{ft}^{-2}\right)$ & 6,333 & 114,7 & 54,33 \\
\hline (n) Índice de Fluxo (admensional) & 0,6085 & 0,3680 & 0,4915 \\
\hline (k) Índice de Consistência (lbf.s $\mathrm{s}^{\mathrm{n}} \cdot 10^{-2} \mathrm{ft}^{-2}$ ) & 0,3198 & 17,37 & 4,550 \\
\hline
\end{tabular}

Analisando os resultados obtido para viscosidade aparente dos Fluidos 1 e 2 é possível notar que a GX sofreu interferência maior do que a CMC quando o adensante utilizado foi adicionado à mistura. Isso foi verificado pela diminuição da consistência observada ao realizar a adição do nitrato de bário ao copo misturador contendo o fluido em produção. Esse fato resultou em valores bastante distintos de viscosidade aparente entre os Fluidos 1 e 2, sendo o Fluido 1 muito menos viscoso que o 2, mesmo apresentando mesma quantidade de agente viscosificante. Logo, seria preciso uma maior quantidade de GX para que fosse possível atingir valores similares ao obtido por uma quantidade fixa de CMC.

Também foi observado uma diferença entre as viscosidades aparentes dos Fluidos 2 e 3 , no entanto ambos os fluidos foram preparados com mesmo tipo de viscosificante em quantidades similares. $\mathrm{O}$ fato do Fluido 3 ter apresentado menor viscosidade aparente se deve a maior quantidade de nitrato de bário adicionada, o que coincide com os resultados observados para o fluido contento GX. É possível sugerir que a adição em maior quantidade desse componente diminuiu o processo de hidratação das cadeias poliméricas dos viscosificantes utilizados e/ou favoreceu a ruptura de algumas interações intermoleculares existentes entre as cadeias polimérias desses agentes. Por esse motivo, todo cuidado deve ser

Persp. Online: exatas \& eng., Campos dos Goytacazes, 28 (10) 17 - 39 - 2020

https://ojs3.perspectivasonline.com.br/ 
tomado quanto a proporção dos componentes que são adicionados ao fluido, pois uma substância com propriedades adensantes pode interferir significativamente na viscosidade da mistura, como observado nesse trabalho.

A viscosidade aparente pode ser relacionada com a viscosidade absoluta $\left(\mu=\Delta \tau . \Delta \gamma^{-1}\right)$, caso compartilhem do mesmo valor o fluido pode ser classificado como newtoniano, desde que apresente limite de escoamento nulo. Esse fato se justifica pelo tipo de modelo reológico, visto que para fluidos newtonianos a viscosidade é um parâmetro constante e independente da tensão de cisalhamento. No entanto, nessa pesquisa foi observado que as viscosidades aparentes obtidas para os fluidos sintetizados foram inferiores as viscosidades absolutas, o que sugere que todas as misturas sintetizadas apresentaram características não newtonianas. Esses resultados também se devem a pseudoplasticidade desse tipo de fluidos. A análise dos valores dos índices de fluxo (n) obtidos para os três fluidos corrobora para essa constatação, visto que todos os três valores foram inferiores a 1 (Tabela 6). De acordo com Borges e colaboradores (2009) quanto mais próximo o índice de fluxo se aproximar desse valor, mais próximo do comportamento Newtoniano o fluido estará. Portanto, dentre os três fluidos sintetizados o que mais se aproxima do modelo Newtoniano é o Fluido 1, que além de apresentar menor variação entre a viscosidade absoluta e a aparente, também apresentou o maior índice de fluxo $(\mathrm{n}=0,6085)$.

Avaliando o Índice de consistência (k) é possível perceber o alto grau de resistência do Fluido 2 diante do escoamento, o que não acontece nos demais fluidos. Por meio desse parâmetro é possível observar que esse fluido apresentou maiores propriedades reológicas ao longo do cisalhamento. Outro fator que proporcionou verificar o tipo de modelo mais apropriado para os fluidos sintetizados é o limite de escoamento $\left(\tau_{\mathrm{L}}\right)$. Esse parâmetro indica o valor mínimo de tensão de cisalhamento a ser aplicado para iniciar o processo de escoamento, sendo não nulo nos casos dos fluidos de Bingham e Herschel-Bulkley (MENEZES et al., 2009; SOUZA et al., 2017). De acordo com Souza e colaboradores (2017), esse parâmetro aumenta à medida que as forças interpartículas aumentam, ou seja, proporciona um aumento no potencial iônico do meio. Isso foi observado para os três fluidos, sendo verificado que as partículas afetaram diretamente os limites de escoamento, resultado em valores não nulos para os três fluidos (Tabela 6). Portanto, esses dados indicam que o modelo de Herschel-Bulkley foi o que mais se adequou aos fluidos sintetizados, como é possível observar na Figura 1.

Para classificação dos fluidos de acordo com a gelificação, foram utilizados os dados presentes na Tabela 7. Esse parâmetro reológico é indicado por basicamente três tipos de forças géis $\left(\mathrm{G}_{0}, \mathrm{G}_{10}\right.$ e $\left.\mathrm{G}_{30}\right)$. De acordo com Borges e colaboradores (2009) esse tipo de força mede a resistência do fluido para ser colocado em fluxo após um determinado tempo em repouso $\left(10 \mathrm{~s}-\mathrm{G}_{0} ; 10 \mathrm{~min}-\mathrm{G}_{10}\right.$ e $\left.30 \mathrm{~min}-\mathrm{G}_{30}\right)$, principalmente devido as manobras a serem realizadas durante o processo de perfuração.

Comparando os dados de $\mathrm{G}_{0}, \mathrm{G}_{10}$ e $\mathrm{G}_{30}$, apresentados na Tabela 7, foi possível classificar os fluidos de perfuração sintetizados de acordo com os seus respectivos comportamentos tixotrópicos. Nesse caso, as misturas obtidas demonstraram ser de gelificação lenta $\left[\mathrm{G}_{0}<\left(\mathrm{G}_{30}+5\right)\right]$ e não progressiva $\left[\Delta \mathrm{G}=\left(\mathrm{G}_{30}-\mathrm{G}_{0}<5\right)\right]$. De acordo com a norma N-2604 da Petrobras (2003) a gelificação rápida é preferível para que seja evitada a sedimentação dos sólidos carreados durante o processo de perfuração. Além disso, a referida

Persp. Online: exatas \& eng., Campos dos Goytacazes, 28 (10) 17 - 39 - 2020

https://ojs3.perspectivasonline.com.br/ 
norma também destaca que a gelificação não progressiva é requerida, pois, caso a viscosidade aumente progressivamente durante o processo de repouso, picos de pressão podem ocorrer após o reinício da perfuração, podendo, inclusive, ser alcançada a pressão de fratura da formação geológica (BORGES et al., 2009; PETROBRAS, 2003).

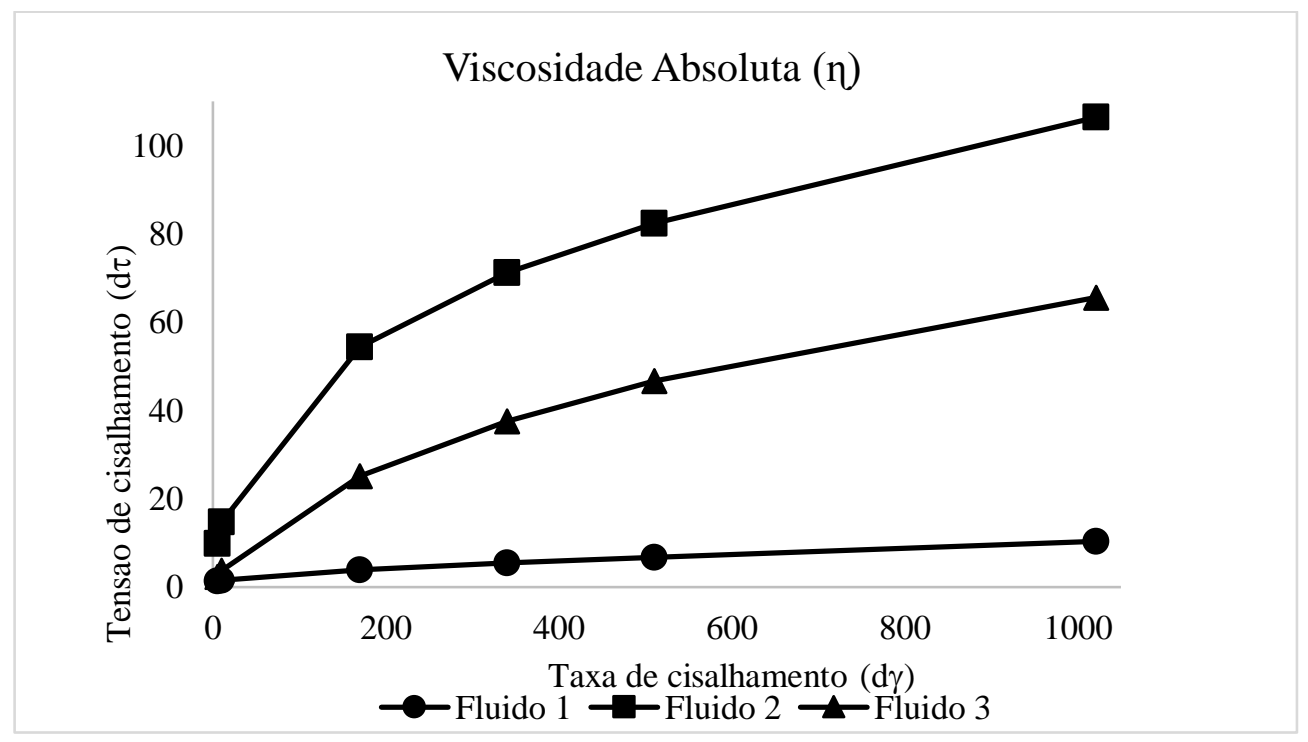

Figura 1: Curvas de fluxo para os Fluidos 1, 2 e 3.

Tabela 7: Análise em triplicatas de força gel dos fluidos de perfuração.

\begin{tabular}{|c|c|c|c|c|c|c|c|c|c|}
\hline & \multicolumn{3}{|c|}{ Fluido $1\left(\right.$ lbf.10 $\left.^{-2} \mathrm{ft}^{-2}\right)$} & \multicolumn{3}{|c|}{ Fluido $2\left(\mathrm{lbf}^{2} 10^{-2} \mathrm{ft}^{-2}\right)$} & \multicolumn{3}{|c|}{ Fluido $3\left({\left.\text { lbf. } 10^{-2} \mathrm{ft}^{-2}\right)}\right.$} \\
\hline & $\mathbf{G}_{0}$ & $\mathbf{G}_{10}$ & $\mathbf{G}_{30}$ & $\mathbf{G}_{0}$ & $\mathbf{G}_{10}$ & $\mathbf{G}_{30}$ & $\mathbf{G}_{0}$ & $\mathbf{G}_{10}$ & $\mathbf{G}_{30}$ \\
\hline 1 & 3,0 & 3,0 & 3,0 & 18 & 19,0 & 18,5 & 4,5 & 5,0 & 5,0 \\
\hline 2 & 3,0 & 3,0 & 2,5 & 18 & 18,5 & 19,0 & 4,5 & 4,5 & 4,5 \\
\hline 3 & 3,0 & 3,0 & 3,0 & 18 & 18,5 & 18,5 & 5,0 & 5,0 & 4,5 \\
\hline Média & 3,0 & 3,0 & 2,8 & 18 & 18,7 & 18,7 & 4,7 & 4,8 & 4,7 \\
\hline Desvio Padrão & 0,0 & 0,0 & 0,3 & 0,0 & 0,288 & 0,288 & 0,29 & 0,29 & 0,29 \\
\hline
\end{tabular}

A N-2604 também sugere que a gelificação inicial $\left(\mathrm{G}_{0}\right)$ mínima ideal para possíveis fluidos de perfuração é equivalente a $7 \mathrm{lbf} \cdot 10^{-2} \mathrm{ft}^{-2}$, enquanto que os valores de $\mathrm{G}_{30}$ não devem ultrapassar a $20 \mathrm{lbf} \cdot 10^{-2} \mathrm{ft}^{-2}$. Portanto, considerando esses parâmetros, somente o Fluido 2 apresentou dados satisfatórios para que pudesse ser aplicado na indústria petrolífera como fluido de perfuração (OLIVEIRA et al., 2013; PETROBRAS, 2003). No entanto, a utilização do nitrato de bário em conjunto com os viscosificantes utilizados resultou em propriedades reológicas além das praticadas nessa indústria, o que pode acarretar excessiva perda de carga no sistema de circulação do fluido de perfuração. 


\subsection{Análises de pH}

O potencial hidrogeniônico $(\mathrm{pH})$ é um parâmetro de grande importância para o processo de produção de um fluido de perfuração, pois caso esteja em uma faixa inapropriada pode colocar todos os equipamentos envolvidos na perfuração em constantes processos de corrosão. O aumento dessa taxa corrosiva acarreta em uma menor vida útil dos equipamentos, o que, consequentemente, resulta em um aumento dos gastos com manutenção (FRAUCHESSANTOS et al., 2013). Além disso, muitos compostos orgânicos, como a grande maioria dos agentes viscosificantes, podem perder suas propriedades físico-químicas dependendo da faixa de $\mathrm{pH}$ a que estão submetidas (NASCIMENTO et al. 2013). Portanto, o controle desse parâmetro foi essencial para síntese dos três fluidos sintetizados nessa (Tabela 8).

Tabela 8: Análise em triplicata de pH dos fluidos de perfuração.

\begin{tabular}{cccc}
\hline & Fluido 1 & Fluido 2 & Fluido 3 \\
\cline { 2 - 4 } $\mathbf{1}$ & 10,8 & 10,9 & 10,7 \\
$\mathbf{2}$ & 10,7 & 10,8 & 10,9 \\
$\mathbf{3}$ & 10,8 & 10,7 & 11,1 \\
\hline Média & 10,8 & 10,8 & 10,9 \\
Desvio Padrão & 0,0577 & 0,100 & 0,200 \\
\hline
\end{tabular}

Os valores obtidos para análise de $\mathrm{pH}$ dos fluidos indicam uma basicidade levemente acima dos níveis desejáveis, visto que os valores requeridos se encontram em uma faixa de 8,5 até 10 . Ou seja, os valores requeridos se encontram em meio alcalino leve, o que geralmente é o ideal para fluidos de perfuração, pois em meio básico a passivação dos metais é favorecida (FRAUCHES-SANTOS et al., 2013). Essa faixa de pH proporciona a diminuição dos problemas ocasionados pela corrosão de equipamentos e, além disso, estão dentro da faixa de trabalho para a Goma Xantana (pH de 2,5 a 11) (NASCIMENTO et al. 2013).

A partir dos resultados obtidos foi possível indicar que a proporção de hidróxido de sódio adicionada poderia ser diminuída para que os fluidos tivessem valores de $\mathrm{pH}$ ideais. Além disso, a proximidade entre os valores de $\mathrm{pH}$ demonstra também que a quantidade de adensante e os tipos de viscosificantes utilizados não vieram a interferir de forma significativa nesse parâmetro.

\subsection{Determinação dos parâmetros de filtração e reboco}

O reboco é um parâmetro de grande importância para impedir que um volume excessivo de filtrado invada a formação, provocando principalmente a instabilidade de formações geológicas, como folhelhos (FARIAS et al., 2006). Os resultados obtidos para os parâmetros de filtração são apresentados na Tabela 9.

Persp. Online: exatas \& eng., Campos dos Goytacazes, 28 (10) 17 - 39 - 2020

https://ojs3.perspectivasonline.com.br/ 
Tabela 9: Parâmetros de filtração e reboco obtidos para os Fluidos 1, 2 e 3.

\begin{tabular}{lccccc}
\hline & & & Fluido 1 & \\
& $\mathbf{1}^{\mathbf{a}}$ & $\mathbf{2}^{\mathbf{a}}$ & $\mathbf{3}^{\mathbf{a}}$ & Média & Desvio Padrão \\
\cline { 2 - 6 } Filtrado $(\mathbf{m L})$ & $>10$ & $>10$ & $>10$ & $>10$ & 0,0 \\
Reboco $(\mathbf{m m})$ & $<1$ & $<1$ & $<1$ & $<1$ & 0,0 \\
\hline
\end{tabular}

\begin{tabular}{lccccc}
\hline & & & Fluido 2 & \\
& $\mathbf{1}^{\mathbf{a}}$ & $\mathbf{2}^{\mathbf{a}}$ & $\mathbf{3}^{\mathbf{a}}$ & Média & Desvio Padrão \\
\cline { 2 - 6 } Filtrado $(\mathbf{m L})$ & 1,0 & 0,4 & 0,5 & 0,6 & 0,3 \\
Reboco $(\mathbf{m m})$ & $<1$ & $<1$ & $<1$ & $<1$ & 0,0 \\
\hline
\end{tabular}

\begin{tabular}{lccccc}
\hline & & & Fluido 3 & \\
& $\mathbf{1}^{\mathbf{a}}$ & $\mathbf{2}^{\mathbf{a}}$ & $\mathbf{3}^{\mathbf{a}}$ & Média & Desvio Padrão \\
\cline { 2 - 6 } Filtrado $(\mathbf{m L})$ & 1,2 & 2,8 & 1,4 & 1,8 & 1,1 \\
Reboco $(\mathbf{m m})$ & $<1$ & $<1$ & $<1$ & $<1$ & 0,0 \\
\hline
\end{tabular}

Na Tabela 9 é possível observar que o fluido que continha GX como agente viscosificante (Fluido 1) foi o que obteve maior valor de filtrado quando comparado aos demais. Apesar da norma N-2604 da Petrobras especificar um limite máximo de $14 \mathrm{~mL}$ de filtrado pelo método API (baixa pressão e baixa temperatura), de modo geral valores elevados desse parâmetro não são requeridos. Além disso, o tamanho do reboco obtido para o Fluido 1 foi relativamente pequeno o que possivelmente interferiu no volume de filtrado.

Os Fluidos 2 e 3 também não obtiveram um valor aceitável para reboco, porém, esses fluidos tiveram como viscosificante a CMC, a qual possui entre as suas funções a de reduzir a infiltração. Esses fluidos demonstraram uma menor quantidade de filtrado se comparado ao Fluido 1, mostrando a eficiência da CMC. Ainda assim, o ideal seria que os três fluidos recebessem adição de substâncias, tais como amido, bentonita ou carbonato de cálcio fino, que permitissem a formação de um reboco mais espesso (MOREIRA, 2012). A adição dessas substâncias é imprescindível para a formação de um reboco homogêneo, visto que os sólidos gerados na perfuração não propiciam essa formação.

\subsection{Determinação da salinidade}

A salinidade é um parâmetro amplo e de grande importância para os fluidos de perfuração. Alguns fluidos necessitam de um maior teor de sal, principalmente em fluidos que precisam ser inibidos para evitar a interação com formações geológicas. No entanto, um alto teor de sal pode ocasionar um aumento na velocidade dos processos corrosivos de equipamentos envolvidos na perfuração, o que é indesejado para indústria petrolífera.

Apesar da quantidade de cloreto de potássio adicionada ser praticamente a mesma nos

Persp. Online: exatas \& eng., Campos dos Goytacazes, 28 (10) 17 - 39 - 2020

https://ojs3.perspectivasonline.com.br/ 
três fluidos, a determinação dessa propriedade pode verificar se a quantidade de adensante e tipos de viscosificantes utilizados podem alterar esse parâmetro. Os resultados obtidos são apresentados nas Tabelas 10 e 11 .

Tabela 10: Resultados obtidos na análise de salinidade em triplicata.

\begin{tabular}{ccccccc}
\hline & \multicolumn{2}{c}{ Fluido 1 } & \multicolumn{2}{c}{ Fluido 2 } & \multicolumn{2}{c}{ Fluido 3 } \\
\cline { 2 - 7 } & Vol. Branco & Vol. Gasto & Vol. Branco & Vol. Gasto & Vol. Branco & Vol. Gasto \\
& $(\mathbf{m L})$ & $(\mathbf{m L})$ & $(\mathbf{m L})$ & $(\mathbf{m L})$ & $(\mathbf{m L})$ & $(\mathbf{m L})$ \\
\cline { 2 - 7 } $\mathbf{1}$ & 2,45 & 8,80 & 1,95 & 9,00 & 1,95 & 8,00 \\
$\mathbf{2}$ & 2,40 & 8,65 & 2,00 & 7,45 & 1,90 & 8,20 \\
$\mathbf{3}$ & 2,45 & 8,70 & 1,85 & 8,30 & 1,80 & 7,95 \\
Média & 2,43 & 8,72 & 1,93 & 8,25 & 1,88 & 8,05 \\
Desvio padrão & 0,0288 & 0,0764 & 0,0764 & 0,776 & 0,0764 & 0,132 \\
\hline
\end{tabular}

Tabela 11: Determinação da concentração de cloreto de sódio nos fluidos de perfuração.

\begin{tabular}{cccc}
\hline & Fluido 1 & Fluido 2 & Fluido 3 \\
\cline { 2 - 4 } Volume final $\mathrm{AgNO}_{\mathbf{3}}(\mathbf{m L})$ & 6,29 & 6,32 & 6,17 \\
Alíquota de filtrado $(\boldsymbol{\mu L})$ & 400 & 400 & 400 \\
Concentração de $\mathbf{N a C l}(\mathbf{g} / \mathbf{L})$ & 9,01 & 9,06 & 8,84 \\
\hline
\end{tabular}

Em geral, os fluidos apresentaram valores próximos e de baixa salinidade, não sendo observada interferência pelos demais aditivos. O sal de cloreto de potássio utilizado teve como intuito o desenvolvimento de sistemas inibidores nos fluidos devido à sua alta capacidade de inibição de folhelhos reativos (NASCIMENTO et al., 2009; JAIN e MAHTO, 2015). Além disso, o controle de salinidade deve ocorrer dependendo do tipo de formação geológica a ser perfurada, para que assim a perfuração seja eficiente e segura.

\subsection{Retorta}

A retorta teve por finalidade determinar os teores de água, óleo e sólidos nos fluidos de perfuração. A partir dos volumes de água e óleo coletados (Tabela 12) foi possível realizar os cálculos para determinação dos parâmetros de retorta apresentados na Tabela 13.

Como esperado, não foram observados quaisquer indícios da presença de uma fração oleosa nos três fluidos sintetizados, sendo esses fluidos compostos majoritariamente por água. Isso, consequentemente, afeta a razão óleo/água, sendo, nesses casos, inexistente para os três fluidos (Tabela 13). Os valores apresentados para o teor de óleo são coerentes para fluidos aquosos que não foram utilizados em processos de perfuração. Essa manobra pode favorecer a

Persp. Online: exatas \& eng., Campos dos Goytacazes, 28 (10) 17 - 39 - 2020 
incorporação de óleo nos fluidos sintetizados, possibilitando a detecção de frações oleosas pelo método de retorta, mesmo em fluidos a base de água.

Tabela 12: Análise de retorta de água e óleo em triplicatas dos fluidos de perfuração.

\begin{tabular}{|c|c|c|c|c|c|}
\hline & \multicolumn{5}{|c|}{ Fluido 1} \\
\hline & 1 & 2 & 3 & Média & Desvio Padrão \\
\hline Retorta (mL de água) & 9,60 & 9,55 & 9,63 & 9,59 & 0,0404 \\
\hline Retorta (mL de óleo) & 0,0 & 0,0 & 0,0 & 0,0 & 0,0 \\
\hline
\end{tabular}

\begin{tabular}{|c|c|c|c|c|c|}
\hline & \multicolumn{5}{|c|}{ Fluido 2} \\
\hline & 1 & 2 & 3 & Média & Desvio Padrão \\
\hline Retorta (mL de água) & 9,90 & 9,85 & 9,80 & 9,85 & 0,0500 \\
\hline Retorta (mL de óleo) & 0,0 & 0,0 & 0,0 & 0,0 & 0,0 \\
\hline
\end{tabular}

\begin{tabular}{lccccc} 
& & \multicolumn{4}{c}{ Fluido 3 } \\
& $\mathbf{1}$ & $\mathbf{2}$ & $\mathbf{3}$ & Média & Desvio Padrão \\
\cline { 2 - 6 } Retorta (mL de água) & 9,45 & 9,35 & 9,50 & 9,43 & 0,0764 \\
Retorta (mL de óleo) & 0,0 & 0,0 & 0,0 & 0,0 & 0,0 \\
\hline
\end{tabular}

Tabela 13: Resultados obtidos após análise de retorta.

\begin{tabular}{|c|c|c|c|}
\hline & Fluido 1 & Fluido 2 & Fluido 3 \\
\hline Teor de óleo em volume $\left[\%\left(v \cdot v^{-1}\right)\right]$ & 0,0 & 0,0 & 0,0 \\
\hline Teor de água em volume $\left[\%\left(\mathrm{v.v}^{-1}\right)\right]$ & 95,9 & 98,5 & 94,3 \\
\hline Massa de óleo coletada (g) & 0,0 & 0,0 & 0,0 \\
\hline Massa de água coletada (g) & 9,60 & 9,85 & 9,43 \\
\hline Massa de sólidos totais (g) & 0,0777 & 0,592 & 2,18 \\
\hline Volume de sólidos totais (mL) & 0,407 & 0,150 & 0,567 \\
\hline Massa específica média de sólidos totais $\left({\left.\mathrm{g} . \mathrm{cm}^{-3}\right)}^{-}\right.$ & 0,191 & 3,94 & 3,84 \\
\hline Teor de sólidos totais em massa $\left[\%\left(\mathrm{~m}^{\left.\left.-m^{-1}\right)\right]}\right.\right.$ & 0,804 & 5,66 & 18,7 \\
\hline Teor de sólidos totais em Volume [\%(v.v $\left.\left.{ }^{-1}\right)\right]$ & 4,067 & 1,500 & 5,667 \\
\hline Massa do fluido de Perfuração (g) & 9,671 & 10,44 & 11,61 \\
\hline Correção da proporção de água $\left[\%\left(v \cdot v^{-1}\right)\right]$ & 96,1 & 98,7 & 94,4 \\
\hline Correção da proporção de sólidos $\left[\%\left(v \cdot v^{-1}\right)\right]$ & 3,9 & 1,3 & 5,6 \\
\hline Razão óleo/água & - & - & - \\
\hline
\end{tabular}

Quanto aos parâmetros relacionados aos teores de sólidos foi observado um aumento

Persp. Online: exatas \& eng., Campos dos Goytacazes, 28 (10) 17 - 39 - 2020

https://ojs3.perspectivasonline.com.br/ 
gradual do Fluido 1 para o Fluido 3. Apesar das duas primeiras misturas apresentarem quantidades similares de sólidos adicionados, foi verificado que a espuma formada pela goma xantana no Fluido 1 afetou o volume inicial, o que acarretou em uma menor quantidade de sólidos totais para esse fluido. Já o Fluido 3 apresentou o maior valor de sólidos totais dentre todas as três misturas sintetizadas. Esse fato é devido a adição de nitrato de bário em quantidade superior às adicionadas nos demais fluidos.

\section{CONCLUSÕES}

Diante dos resultados apresentados nesse trabalho foi possível obter três misturas com diferentes composições químicas, as quais foram avaliadas frente a diferentes análises físicoquímicas, com intuito de verificar a possibilidade de implementação dessas misturas como possíveis fluidos de perfuração. A GX utilizada no Fluido 1 sofreu grande interferência do adensante utilizado, sendo perceptível uma grande incompatibilidade entre esses compostos na confecção de fluidos de perfuração. O referido viscosificante também afetou consideravelmente a densidade do Fluido 1, por consequência da maior formação de espumas, o que poderia ser minimizado por um envelhecimento do fluido em temperatura adequada, demonstrando o quanto essa etapa é de grande importância para confecção dos fluidos de perfuração. A CMC, apresentou alguns parâmetros de viscosidade desejáveis, além de demonstrar ser efetiva em sua função secundária como redutora de filtrado, sendo esse polímero menos afetado do que a GX pelo adensante utilizado. Ademais foi verificado espessuras muito finas de reboco paras os três fluidos obtidos, sendo, portanto, necessária a adição de compostos com a finalidade de aumentar essa espessura. Outro aditivo que merece destaque nesse trabalho é o nitrato de bário, visto que o seu uso é incomum no processo de preparo e adensamento de fluidos de perfuração. A alta solubilidade desse composto não melhorou as propriedades físico-químicas dos fluidos, não promovendo uma eficiência de adensamento. Além disso, a utilização desse aditivo possivelmente dificultou a hidratação dos polímeros utilizados, indicando que esse composto não tem potencial para ser utilizado na composição desse tipo de fluido. Situações como essas levam a perceber a importância de avaliar as funções e as modificações que os aditivos podem causar nos fluidos, sendo de forma positiva ou negativa. Apesar dos fluidos apresentarem baixo potencial industrial acredita-se que é importante perpetuar os conhecimentos científicos, para que assim outros estudos possam ser direcionados a partir desse trabalho.

\section{REFERÊNCIAS}

AMORIM, L. V.; FARIAS, K. V.; VIANA, J. D.; BARBOSA, M. I. R.; PEREIRA, E.; FRANÇA, K. B.; LIRA, H. L.; FERREIRA, H. C. Water based drilling fluids. Part I: Effects of polymeric additives in the rheological properties. Cerâmica, v. 51, p. 128-138, 2005. DOI: $10.1590 / \mathrm{S} 0366-69132005000200010$

AQUINO, F. N. P. M.; COSTA, L. F. L. G. Riscos Ambientais em uma Sonda de Perfuração de Petróleo Onshore na Unidade de Negócios-RN/CE-Mossoró/RN. Holos, v. 3, p. 64-83, 2011.

Persp. Online: exatas \& eng., Campos dos Goytacazes, 28 (10) 17 - 39 - 2020

https://ojs3.perspectivasonline.com.br/ 
AZEVEDO, D. A.; SILVA, T. F; SILVA, D. B. Avaliação Geoquímica de Biomarcadores Ocluídos em Estruturas Asfaltênicas. Química Nova, v. 32, n. 7, p. 1770-1776, 2009. DOI:10.1590/S0100-40422009000700017

BARBOSA, M. I. R.; AMORIM, L. V.; BARBOZA, K. R. A.; FERREIRA, H. C. Desenvolvimento de compósitos bentonita/polímeros para aplicação em fluidos de perfuração. Matéria, v. 12, n. 2, p. 367-372, 2007. DOI:10.1590/S1517-70762007000200015

BHANDARI, J.; ABBASSI, R.; GARANIYA, V.; KHAN, F. Risk analysis of deepwater drilling operations using Bayesian network. Journal of Loss Prevention in the Process Industries, v. 38, p. 11-23, 2015. DOI:10.1016/j.jlp.2015.08.004

BORGES, C. D.; VENDRUSCOLO, C. T.; MARTINS, A. L.; LOMBA, R. F. T. Rheological behaviour of xanthan produced by Xanthomonas arboricola pv pruni for application in fluid of oil well perforation. Polímeros: Ciência e Tecnologia, v. 19, n. 2, p. 160-165, 2009. DOI:10.1590/S0104-14282009000200015

BYAKAGABA， P.; MUGAGGA， F.; NNAKAYIMA， D. The socio-economic and environmental implications of oil and gas exploration: Perspectives at the micro level in the Albertine region of Uganda. The Extractive Industries and Society, v. 6, n. 2, p. 358-366, 2019. DOI:10.1016/j.exis.2019.01.006

CAENN, R.; CHILLINGAR, G. V. Drilling fluids: State of the art. Journal of Petroleum Science and Engineering, v. 14, n. 3, p. 221-230, 1996. DOI:10.1016/0920-4105(95)000518

CURBELO, F. D. S.; ARANHA, R. M.; ARAÚJO, E. A.; FREITAS, J. C. O.; GARNICA, A. I. C. Remoção de Fluido de Perfuração Base óleo por Colchões Lavadores Compostos por Óleo Vegetal, Tensoativo e Salmoura. Holos, v. 4, p. 125-134, 2017. DOI:10.15628/holos.2017.5631

ECCARD, L. S.; QUARTO, L. C.; SOUZA, S. M. F.; QUARTO, J. V. C.; MUNIZ, V. F. S. G. Análise de Parâmetros dos Fluidos de Perfuração de Poços de Petróleo. Revista Transformar, v. 12, n. 2, p. 124-146, 2018.

FARIAS, K. V.; AMORIM, L. V.; FERREIRA, H. C.; PEREIRA, E. Study of rheology and filter-cake thickness of drilling fluids: influence of anionic dispersants and surfactant. Cerâmica, v. 52, n. 324, p. 307-314, 2006. DOI:10.1590/S0366-69132006000400015

FARIAS, K. V.; AMORIM, L. V.; LIRA, H, L.Desenvolvimento de fluidos aquosos para aplicação em perfuração de poços de petróleo - Parte I. Revista Eletrônica de Materiais e Processos, v. 4, n. 1, p. 14-25, 2009.

FERREIRA, P.; PEREIRA, É.; SILVA, M. The relationship between oil prices and the Brazilian stock market. Physica A: Statistical Mechanics and Its Applications, v. 545, 123745, 2020. DOI:10.1016/j.physa.2019.123745

Persp. Online: exatas \& eng., Campos dos Goytacazes, 28 (10) 17 - 39 - 2020

https://ojs3.perspectivasonline.com.br/ 
FISCHER, P. W.; COOK, J. F. Drilling Fluid - Assignors to Union Oil Company of California, United States Patent Office, Los Angeles, California, No 16.145, 1951.

FRAUCHES-SANTOS, C.; ALBUQUERQUE, M. A.; OlIVEIRA, M. C. C.; ECHEVARRIA, A. A. Corrosão e os Agentes Anticorrosivos. Revista Virtual de Química, v. 6 , n. 2, p. 293-309, 2014. DOI:10.5935/1984-6835.20140021

FRERET, V. A. C.; CHAVES, H. A. F.; JONES, C. M. Evolução do Consumo e Produção de Petróleo no Período de 1965 a 2015. Anuário do Instituto de Geociências - UFRJ, v. 42, n. 1, p. 642-655, 2019.

GASTALDI, F. C.; MENDONÇA, F. Petróleo, armas e dinheiro: A Arábia Saudita e o poder global dos Estados Unidos (2001 - 2018). Oikos, v. 18, n. 12, p. 55-65, 2019.

JAIN, R.; MAHTO, V. Evaluation of polyacrylamide/clay composite as a potential drilling fluid additive in inhibitive water based drilling fluid system. Journal of Petroleum Science and Engineering, v. 133, p. 612-621, 2015. DOI:10.1016/j.petrol.2015.07.009

JANSEN, J. D.; VAN DEN STEEN, L. Active damping of self-excited torsional vibrations in oil well drillstrings. Journal of Sound and Vibration, v. 179, n. 4, p. 647-668, 1995. DOI:10.1006/jsvi.1995.0042

KEMBAIYAN, K. T.; KESHAVAN, K. Combating severe fluid erosion and corrosion of drill bits using thermal spray coatings. Wear, v. 186-187, p. 487-492, 1995. DOI:10.1016/00431648(95)07142-3

MACHADO, J.C.V. Reologia e escoamento de fluidos - Ênfase na indústria do petróleo, Rio de Janeiro: Ed. Interciência Ltda., 2002. 257p.

MAHMOUD, S. A.; DARDIR, M. M. Synthesis and Evaluation of a New Cationic Surfactant for Oil-Well Drilling Fluid. Journal of Surfactants and Detergents, v. 14, n. 1, p. 123-130. 2010. DOI:10.1007/s11743-010-1214-7

MAHTO, V.; SHARMA, V. P. Rheological study of a water based oil well drilling fluid. Journal of Petroleum Science and Engineering, v. 45, n. 1-2, p. 123-128, 2004. DOI:10.1016/j.petrol.2004.03.008

MATTA, G; GJYLI, L. Inorganic Toxicity: Environment \& Human Health. Lambert Academic Publishing. Heinrich-Böcking-Straße 6, 66121 Saarbrücken, Germany, p. 65-87, 2018.

MELO, K. C.; DANTAS, T. N. C.; BARROS NETO, E. L. Influência da Tecnologia na Reologia dos Fluidos de Perfuração Preparados com Carboximetilcelulose, Goma Xantana e Bentonita. Holos, v. 5, p. 3-18, 2013.

MENEZES, R. R.; CAMPOS, L. F. A.; FERREIRA, H. S. MARQUES, L. N.; NEVES, G. A. FERREIRA, H. C. Rheological behavior study of bentonite clays from Cubati, Paraíba, Brazil. Cerâmica, v. 55, p. 349-355, 2009. DOI:10.1590/S0366-69132009000400003

Persp. Online: exatas \& eng., Campos dos Goytacazes, 28 (10) 17 - 39 - 2020

https://ojs3.perspectivasonline.com.br/ 
MOREIRA, B. A.; AROUCA, F. O.; DAMASCENO, J. J. R. Avaliação da permeabilidade de meios porosos constituídos por carbonato de cálcio utilizado como agente obturante em processos de perfuração de poços de petróleo. Exacta, v. 10, n. 3, p. 341-348, 2012. DOI:10.5585/Exacta.v10n3.3908

NASCIMENTO, R. C. A. M.; VIEIRA, T. M.; AMORIM, L. V.; LIRA, H. L. Avaliação da eficiência de inibidores de argilas expansivas para uso em fluidos de perfuração. Revista Eletrônica de Materiais e Processos, v. 4, n. 2, p. 12-19, 2009.

NASCIMENTO, R. A. de M.; MAGALHÃES, J.; PEREIRA, E.; AMORIM, L. V. Degradação térmica de fluidos de perfuração argilosos aditivados com polímeros e lubrificante Thermal degradation of clay drilling fluids with polymers and lubricant additives. Matéria, v. 18, n. 2, p. 1329-1339, 2013. DOI:10.1590/S1517-70762013000200009

NASIRI, M.; ASHRAFIZADEH, S. N.; GHALAMBOR, A. Synthesis of a Novel Ester-Based Drilling Fluid Applicable to High Temperature Conditions. Journal of Energy Resources Technology, v. 131, n. 1, 2009. DOI:10.1115/1.3066367

OLIVEIRA, G. M.; FRANCO, A. T.; NEGRAO, C. O.; MARTINS, A. L., SILVA, R. A. Modeling and validation of pressure propagation in drilling fluids pumped into a closed well. Journal of Petroleum Science and Engineering, v. 103, p. 61-71, 2013. DOI:10.1016/j.petrol.2013.02.012

PETROBRAS. Viscosificante para fluidos usados na exploração e produção de poços de petróleo e gás - Especificação, N-2604, 2003.

PIQUET, R.; SERRA, R. V. Petróleo e região no Brasil: o desafio da abundância. Rio de Janeiro: Editora Garamond, 2007. 352p.

PIQUET, R.; TAVARES, E.; PESSÔA, J. M. Emprego no setor petrolífero: dinâmica econômica e trabalho no Norte Fluminense. Cadernos Metrópole, v. 19, n. 38, p. 201-224, 2017. DOI:10.1590/2236-9996.2017-3808

QUEIROZ-NETO, J. C.; BISCAIA-JR, E. C.; PETRI, D. F. S. Estudo sobre a adsorção do fluido de perfuração salgado contendo polímeros sobre $\mathrm{SiO}_{2}$. Química Nova, v. 30, n. 4, p. 909-915, 2007. DOI:10.1590/S0100-40422007000400028

SOUZA, G. S.; LUPORINI, S., RIGOLI, I. C. Caracterização reológica de suspensões argilosas salinas com goma xantana para fluidos de perfuração de poços de petróleo. Matéria, v. 22, n.1, p. 2017. DOI:10.1590/S1517-707620170001.0128

SORGARD, E.; ALTERAS, E.; HYDRO, N.; FIMREITE, G.; DZIALOWSKI, A.; SVANES, G. S. Design of Water Based Drilling Fluid Systems for Deepwater Norway. In: SPE/IADC Drilling Conference, 2001, Amsterdam. Society of Petroleum Engineers, 2001. DOI:10.2118/67834-ms

TERRA, W. S.; MARTINS, L. L.; CRUZ, G. F. Avaliação da Eficiência de Diferentes Solventes Orgânicos na Precipitação de Asfaltenos de Petróleos Brasileiros e Análise das

Persp. Online: exatas \& eng., Campos dos Goytacazes, 28 (10) 17 - 39 - 2020

https://ojs3.perspectivasonline.com.br/ 
Frações Asfaltênicas e Maltênicas por Diferentes Técnicas Instrumentais. Revista Virtual de Química, v. 11, n. 4, p. 1364-1376, 2019. DOI:10.21577/1984-6835.20190093

THOMAS, J. E. Fundamentos de engenharia de petróleo. Rio de Janeiro: Ed. Interciência Ltda, 2001. 271p.

TRINDADE, W. L.; BRANCO, C. C. M. The Offshore Heavy Oil Development Challenges in Brazil. SPE Latin American and Caribbean Petroleum Engineering Conference. SPE 97381, 2005. DOI:10.2118/97381-ms

VANDENBUSSCHE, V.; BERGSLI, A.; BRANDT, H.; BRUDE, O. W. W.; NISSEN-LIE, T. R. Well-specific Blowout Risk Assessment. International Conference on Health, Safety and Environment in Oil and Gas Exploration and Production. SPE 157319, 2012. DOI:10.2118/157319-ms 